\title{
Effects of exposure to artificial lighting on orientation of hatchling sea turtles on the beach and in the ocean
}

\author{
Jacquelyn Kay Lorne, Michael Salmon* \\ Department of Biological Sciences, Florida Atlantic University, Box 3091, 777 Glades Road, Boca Raton,
} Florida 33431—0991, USA

\begin{abstract}
Artificial lighting disrupts sea turtle hatchling orientation from the nest to the sea. We studied how a light-induced landward crawl affects the later ability of hatchlings to crawl to the sea, and to swim away from the shore from a dark beach. A brief ( $2 \mathrm{~min}$ ) landward crawl had no effect on swimming orientation as long as surface waves were present. In a calm sea, landward-crawling hatchlings failed to swim offshore, while those crawling seaward were well oriented. A long $(2 \mathrm{~h})$ crawl toward a landward light source, however, impaired the ability of hatchlings to crawl seaward. These results demonstrate that orientation toward artificial light sources compromises the ability of hatchlings to respond to natural orientation cues, both on land and in the sea. Based on these results, we suggest several changes to current management practices used when releasing misoriented turtles in the wild.
\end{abstract}

KEY WORDS: Sea-finding - Orientation - Migration - Sea turtle $\cdot$ Loggerhead $\cdot$ Caretta caretta Photopollution

Resale or republication not permitted without written consent of the publisher

\section{INTRODUCTION}

Sea turtle hatchlings emerge at night from underground nests on sandy beaches and crawl directly to the sea. They locate the ocean from the nest using visual cues (reviewed by: Lohmann et al. 1997). Hatchlings orient away from elevated, darker, landward silhouettes and orient toward the open, lower, brighter seaward horizon (Limpus 1971, Salmon et al. 1992). Once hatchlings enter the sea, they swim offshore by orienting into surface waves (Salmon \& Lohmann 1989, Lohmann et al. 1990, Lohmann \& Lohmann 1992).

Hatchlings also use a 'magnetic compass' to orient offshore but before this is used it must be 'calibrated,' or set, by previous experience (Lohmann \& Lohmann 1994). Under laboratory conditions, calibration is accomplished either by crawling in one direction (toward a light source; Lohmann et al. 1995) or by swimming in one direction either toward a light source (Lohmann 1991) or into surface waves (Goff et al. 1998).

These results indicate that to reach their migratory goals, hatchlings must respond to specific cues that guide their orientation from the nest to the sea, and away from the beach. Artificial night lighting degrades the visual environment at many nesting beaches and can disrupt the ability of hatchlings to either detect or respond to the cues required for an oriented crawl (Witherington \& Martin 1996, Witherington 1997, Salmon 2003, Tuxbury \& Salmon 2005). Even if these turtles ultimately locate the sea from illuminated beaches, they usually swim more slowly and on less direct paths (Witherington 1991).

Artificial lighting disrupts hatchling orientation on the beach in 2 ways. The turtles may crawl towards the lights ('misorientation') or they may be incapable of crawling in any direction ('disorientation'; Verheijen 1985). As a consequence, turtles may crawl for hours without reaching the sea and become exhausted and dehydrated. A prolonged beach crawl also increases their exposure to predators (Witherington \& Martin 1996). Tens of thousands of hatchlings die each year as a consequence of disrupted orientation caused by artificial lighting (Witherington 1997). A disrupted crawl might prevent the turtles from calibrating their magnetic compass or result in miscalibration so that after they enter the sea, they swim in inappropriate directions. 
Misoriented or disoriented hatchlings are sometimes found alive on the beach, either late at night or the morning after failing to locate the sea. Current Florida Fish and Wildlife Conservation Commission (2002) guidelines for Florida, USA, (hereafter, Guidelines) state that disoriented hatchlings found at night should be released immediately or (if found later) in the morning before 09:00 $\mathrm{h}$, or the next evening. If these turtles fail to crawl seaward, the Guidelines recommend that hatchlings should be moved closer to the water, or released in shallow water near the shore.

But are turtles treated in this manner capable of normal offshore orientation? The Guidelines assume they are, but there are no data to support this conclusion. The purpose of the present study was to determine whether turtles that have been previously misoriented by artificial lighting can recover from that experience, and orient normally. The following questions were addressed: (1) Can a hatchling that has crawled for a short time in an inappropriate direction swim away from the shore ('offshore', defined as heading to the $\mathrm{NE}, \mathrm{E}$, or SE) in the presence or absence of surface waves? (2) Does the duration of a misdirected crawl affect a hatchling's ability to respond to normal orientation cues on land and in the ocean?

\section{MATERIALS AND METHODS}

Turtles. Our study was conducted from July through September 2005. Loggerhead Caretta caretta L. hatchlings were obtained from a hatchery in Pompano Beach, Broward County, Florida, USA (26 $14^{\prime} 5.34^{\prime \prime} \mathrm{N}$, $\left.80^{\circ} 7^{\prime} 32.34^{\prime \prime} \mathrm{W}\right)$. Nests that were near the end of incubation ( $\geq 50 \mathrm{~d}$ ) were inspected in the afternoon. If there was a depression above the nest (indicating an emergence would occur later that evening), 10 hatchlings were removed from each nest without disturbing the remaining turtles.

Captured turtles were placed on a shallow layer of moist sand inside a light-tight Styrofoam ${ }^{\circledR}$ box and transported about $10 \mathrm{~km}$ to our laboratory at Florida Atlantic University (Boca Raton campus). They were stored there for short periods (until dark), and then transported by car to a dark beach (Gulfstream Beach, Palm Beach County, Florida, USA; 26²9'14.3" N, $\left.80^{\circ} 3^{\prime} 12.7^{\prime \prime} \mathrm{W}\right)$ where the experiments were conducted.

Experiments. Two experiments were completed. Short crawl tests were carried out to determine how a brief crawl in the wrong direction affected the ability of hatchlings to swim away from the shore. Crawl duration tests were carried out to determine whether the length of time that turtles crawled in the wrong direction affected their subsequent ability to find the sea.
Turtles that swam away from the shore were recaptured and released in the ocean. Turtles that swam in other directions were recaptured, released on the beach, crawled to the surf zone, and entered the sea on their own.

Short crawl tests. Forty turtles (20 control and 20 experimental turtles, in equal numbers from 10 nests) were used in this experiment. Control turtles crawled east (toward the ocean), whereas experimental turtles crawled west (toward land). Ten turtles in each group were tested on nights when surface waves were present; an equal number were tested in the absence of waves (sea surface calm). Ideally, the no-wave and wave experiments should have been performed on the same evening. However, both conditions never occurred on the same night and thus experiments could only be carried out on different evenings.

Experiments began by placing a hatchling inside an empty circular $(1.6 \mathrm{~m}$ diameter $\times 25 \mathrm{~cm}$ deep) plastic arena, painted flat black (Fig. 1). Each hatchling was fitted with a small rubber band around its body just behind the foreflippers. One end of a $20 \mathrm{~cm}$ long monofilament line was tied to the rubber band; the opposite end was tied to a string stretched over the center of the arena (Fig. 1A). This arrangement allowed the tethered hatchling to crawl in any direction without contacting the arena wall.

A small area of the arena wall was illuminated by a battery powered white light-emitting diode (LED; Fig. 1A). The LED was turned on for 2 min, inducing the turtle to crawl toward the light. For the control hatchlings the light came from the east while for the experimental hatchlings the light came from the west. The arena was rotated to change light direction. All hatchlings crawled toward the light.

After each turtle had completed its crawl, it was placed in shallow water $\sim 1 \mathrm{~m}$ from the surf zone. Because swimming hatchlings are difficult to see at night, each turtle towed a 'Witherington' float. The float was a $6 \mathrm{~cm}$ long $\times 1.3 \mathrm{~cm}$ diameter round balsa wood dowel, pointed at both ends (Fig. 1B). The float contained a weight attached to its bottom surface, and a groove housing a $2 \mathrm{~cm}$ long cynalume (chemical) light was carved into its top surface. The light was activated just before the float was used. The float was attached to the turtle with a $2 \mathrm{~m}$ long length of thin cotton thread, tied to the rubber band. The swimming turtle was then followed at a distance of $\sim 10 \mathrm{~m}$ by an observer in a kayak. Hatchlings do not respond to the presence of objects 1.5 to $30 \mathrm{~m}$ behind them (Frick 1976, Ireland et al. 1978, Lohmann \& Lohmann 1992, Witherington 1991).

Pulling a float retards a hatchling's swimming speed by $\sim 15 \%$, but has no effect on the turtle's orientation (Stewart \& Wyneken 2004). When waves were present, wave direction was measured after each trial by sight- 

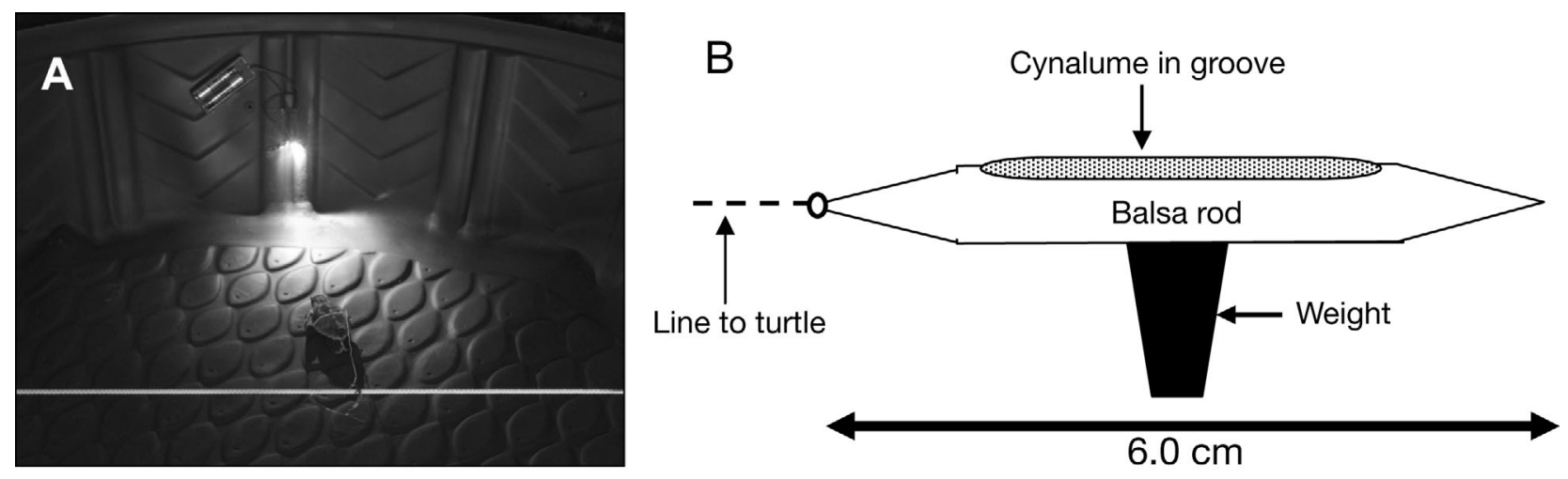

Fig. 1. (A) Arena (circular dry plastic enclosure painted flat black) and light used at the beach to attract a tethered loggerhead. Each hatchling was placed inside the arena and fitted with a small rubber band, attached by a short monofilament line to the center of the arena. The arena was rotated to present its light from either the east (toward the ocean) or the west (toward land). (B) A 'Witherington' float used to track a hatchling's movements as it swam away from the shore. See 'Materials and methods' for details

ing across the wave propagation axis with an electronic compass (KVH Datascope ${ }^{\circledR}$ ).

The turtle's location as it swam was recorded at 4 locations as waypoints on a GPS (WAAS Garmin Geko $201^{\mathrm{TM}}$, accuracy: $\pm 5 \mathrm{~m}$ ): its release site in shallow water and its location after swimming for 5, 10, and $15 \mathrm{~min}$. Tests each evening ended after an equal number (up to 4 individuals) of control and experimental hatchlings had been tested. Tests on consecutive evenings continued until target sample size (40 turtles from 10 nests) had been achieved.

At the study site, the alongshore current altered hatchling swimming direction and distance. To correct for current, we measured the displacement of a small water-filled plastic jug containing just enough air to float near the water surface. The jug was placed in shallow water about $100 \mathrm{~m}$ from shore. Its GPS position was recorded at the beginning and at the end of two $15 \mathrm{~min}$ 'drift' periods: one just before tests began, and a second later that night after tests ended. The 2 measurements were then averaged in distance and direction. While this procedure was spatially adequate (because hatchlings swim near the surface), it lacked temporal precision (because current magnitude can change through time). However, this technique sufficed to characterize differences between turtles that could, and could not, swim away from the shore.

The 2 drift GPS locations (in decimal degrees) were entered into 2 websites: www.csgnetwork.com/ latlongdistcalc.html (for distance) and www.csgnetwork. com/aviationbrgrngcalc.html (for direction). Distance and direction were then combined to determine the magnitude of current displacement.

The following procedures were used to correct for the influence of current. Turtles were placed in shallow water, within $1 \mathrm{~m}$ of the beach. Since no current was evident at this location, no correction was made at the release site. When turtles swam 'offshore', their locations were adjusted for current by exposure time. For example, if the drift bottle moved north by $100 \mathrm{~m}$ in $15 \mathrm{~min}$, the turtle's 4 th position was corrected southward by $100 \mathrm{~m}$, its 3rd position by $66 \mathrm{~m}$, and its $2 \mathrm{nd}$ position by $33 \mathrm{~m}$.

Each turtle's swimming path (based upon its corrected location) was determined by entering the data into Maptool (2002, see www.seaturtle.org/maptool/). A line connected each of the hatchlings' locations into a single swimming path. Its 'offshore direction' (average bearing) was determined by the angle formed between the release point and the turtle's final (15 min) corrected position.

Crawl duration tests. Hatchlings were divided into 3 groups of 10 turtles each. One group crawled in the arena for $2 \mathrm{~h}$ toward a west-facing light. A second group crawled toward the same west light for $2 \mathrm{~min}$. A third (control) group was left undisturbed inside a light-tight Styrofoam ${ }^{\circledR}$ box placed on the beach next to the arena. Experiments were completed with at least 1 turtle in each group every evening until the sample size ( $\mathrm{n}=10$ hatchlings/treatment) was achieved. The hatchlings used each evening came from the same nest, but turtles tested on different evenings came from different nests.

After their initial treatment, hatchlings from each group were released at the same location on the beach (13 $\mathrm{m}$ from the surf zone). Each turtle's crawling path and time to locate the sea (or the passage of $25 \mathrm{~min}$, whichever occurred first) were recorded. The turtle's path was traced as field notes by an observer, following about $3 \mathrm{~m}$ behind the animal. An electronic compass (KVH Datascope ${ }^{\circledR}$ ) was used to measure each turtle's crawl direction (angle measured between the release and the recapture site). 
Immediately after completing its crawl, a Witherington float was attached to each turtle before it was released in shallow water. Waves were always present. The turtle's orientation while swimming was recorded for $15 \mathrm{~min}$, and then corrected for any effects of current on distance or direction (see 'Short crawl tests'). At the end of the trial, each turtle was recaptured, its rubber band removed, and the animal was released. Wave direction was measured after each trial.

Statistical analyses. Analysis of crawling duration and swimming distance: A Shapiro-Wilk test (Zar 1999) was used to determine whether crawling durations and swimming distances within each treatment group were normally distributed. When this was the case, comparisons between groups were made using a 2-way ANOVA (Zar 1999). When significant $F$ values were obtained, post hoc Tukey tests were used to identify the group(s) responsible. When distributions were skewed, these comparisons were made using KruskalWallis tests (Zar 1999).

Orientation: Circular statistics (Zar 1999) were used to analyze crawling and swimming orientation. The data for each group were pooled to determine a second-order (group) mean angle and r-vector (dispersion). Rayleigh tests were used to determine whether each group showed significant orientation (Zar 1999). Watson-Williams tests were used to compare orientation between different crawling and swimming groups. Kruskal-Wallis tests were used to analyze dispersion among the groups. The null hypothesis of no statistical differences among groups was rejected when $\mathrm{p} \leq 0.05$.

\section{RESULTS}

\section{Short crawl tests}

Swimming distance

The distribution of swimming distances within the 4 groups was normal (Shapiro-Wilk p values ranged between 0.15 and 0.99). Both crawl direction (east vs. west; $F=11.08, \mathrm{p}=0.002$ ) and oceanic conditions (waves vs. no waves; $F=18.57$, p < 0.0001) significantly affected swimming distance (Table 1). There was also a significant interaction between crawl direction and ocean conditions $(F=11.31, \mathrm{p}=0.002 ;$ Table 2$)$. Post hoc Tukey tests indicated that the hatchlings that had crawled west and swam when there were no waves swam shorter distances from shore than the remaining groups (which did not differ significantly from one another).
Table 1. Distances (mean $\pm \mathrm{SE}$ ) turtles swam from shore during a $15 \mathrm{~min}$ trial. Hatchlings initially crawled to the east or west inside an arena (crawl direction). Half of the turtles (total $n=40$ ) then swam on evenings when there were waves and half when there were no waves (oceanic conditions)

\begin{tabular}{|llr}
\hline $\begin{array}{l}\text { Crawl } \\
\text { direction }\end{array}$ & Oceanic conditions & Distance $(\mathrm{m})$ \\
\hline East & Waves & \\
& No waves & $180.7 \pm 10.6$ \\
West & Waves & $167.1 \pm 12.4$ \\
& No waves & $70.6 \pm 17.8$ \\
& & \\
\hline
\end{tabular}

Orientation

In the presence of waves, hatchlings that had previously crawled east or west swam to the east (Fig. 2). Both groups were significantly oriented (east group Rayleigh $\mathrm{z}=9.25, \mathrm{p}<0.05$; west group Rayleigh $\mathrm{z}=$ 7.88 ; $\mathrm{p}<0.05$ ), and did not differ statistically (WatsonWilliams $F=-0.12$, not significant, ns).

In the absence of waves (Fig. 2), east crawling turtles swam east and were significantly oriented (Rayleigh $\mathrm{z}$ $=9.77, \mathrm{p}<0.05)$. However, turtles that crawled west were not oriented as a group (Rayleigh $\mathrm{z}=1.97$, ns). Five turtles swam in directions parallel to shore while one remained at the release site. One hatchling swam away from the shore, then reversed direction and returned. Three other turtles swam away from the shore (Fig. 2).

There were no significant differences in dispersion among the 3 groups that oriented away from the shore (Kruskal-Wallis $H=2.90$, ns).

\section{Crawl duration tests}

Crawling duration

Both the control and the 2 min west groups crawled to the ocean in 9.3 and $9.1 \mathrm{~min}$, respectively, whereas the turtles that crawled to the west for $2 \mathrm{~h}$ on average took $14.4 \mathrm{~min}$ to reach the sea (Fig. 3). Two turtles in

Table 2. 2-way ANOVA of the swimming distances achieved by the 4 groups of hatchlings shown in Table 1. Condition: oceanic condition (waves or no waves);

\begin{tabular}{|lcrrrr|}
\hline $\begin{array}{l}\text { Source of } \\
\text { variation }\end{array}$ & df & \multicolumn{1}{c}{ SS } & MS & $F$ & $p$ \\
\hline Direction & 1 & 23036.6 & 23036.6 & 11.8 & 0.002 \\
Condition & 1 & 38621.9 & 38621.9 & 18.6 & 0.001 \\
Interaction & 1 & 23532.7 & 23532.7 & 11.3 & 0.002 \\
Within & 36 & 74881.0 & 2080.0 & & \\
Total & 39 & 160072.2 & & & \\
\hline
\end{tabular}




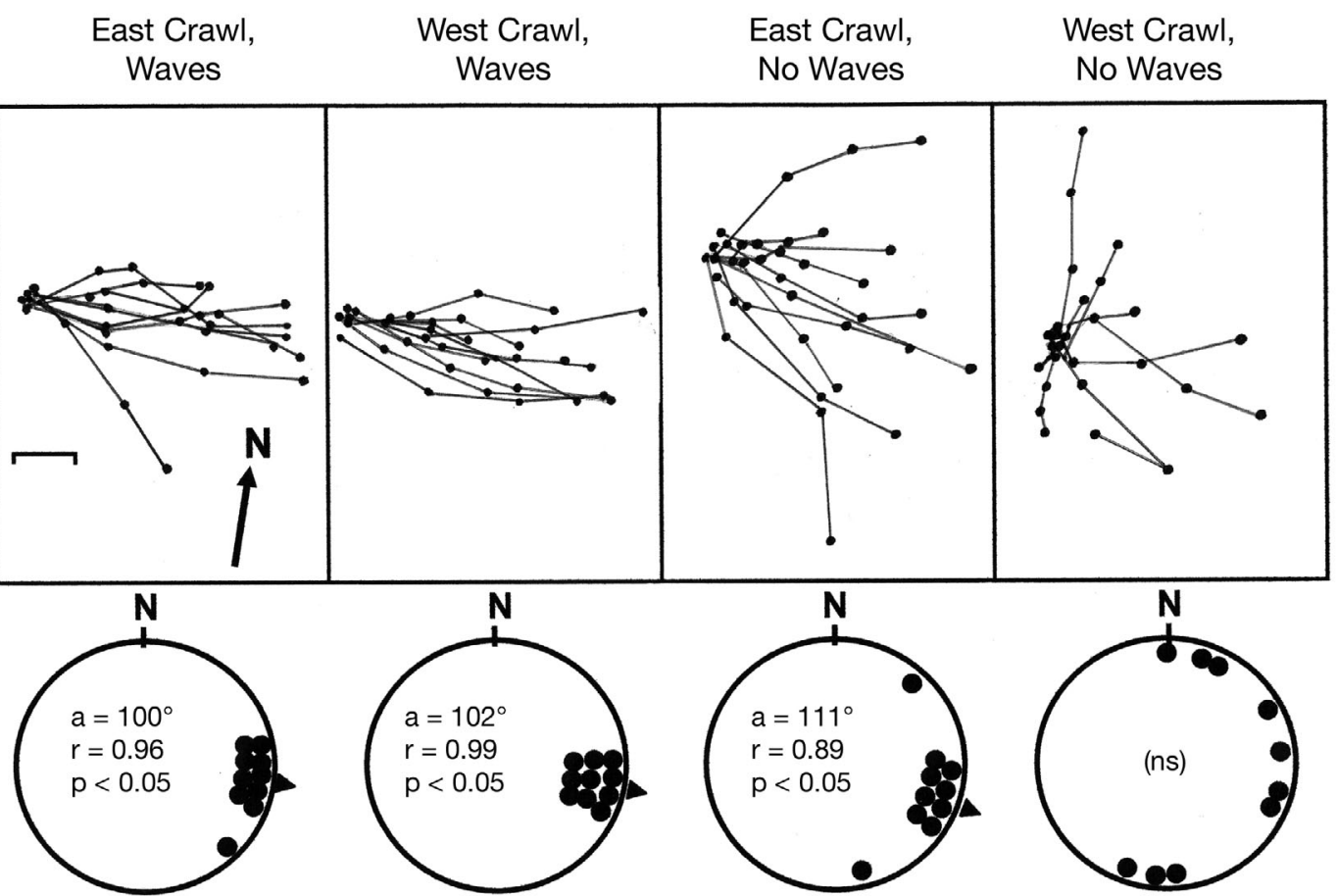

Fig. 2. Top panels: swimming paths and distances achieved over 15 min for hatchlings that initially crawled east or west for 2 min. Scale bar: $50 \mathrm{~m}$. Bottom panels: orientation by the turtles in each treatment in the presence or absence of waves.

a, mean angle; r: r-vector; ns: not significant. Probabilities are based upon the outcome of Rayleigh tests

this group (out of the 10 tested) failed to locate the ocean within $15 \mathrm{~min}$, and were excluded from this analysis. Crawling times of the 3 groups showed a normal distribution (Shapiro-Wilk test, p values ranged between 0.25 and 0.77 ). The 3 groups differed statistically (1-way ANOVA; $F=4.991, p<0.02)$. Post hoc

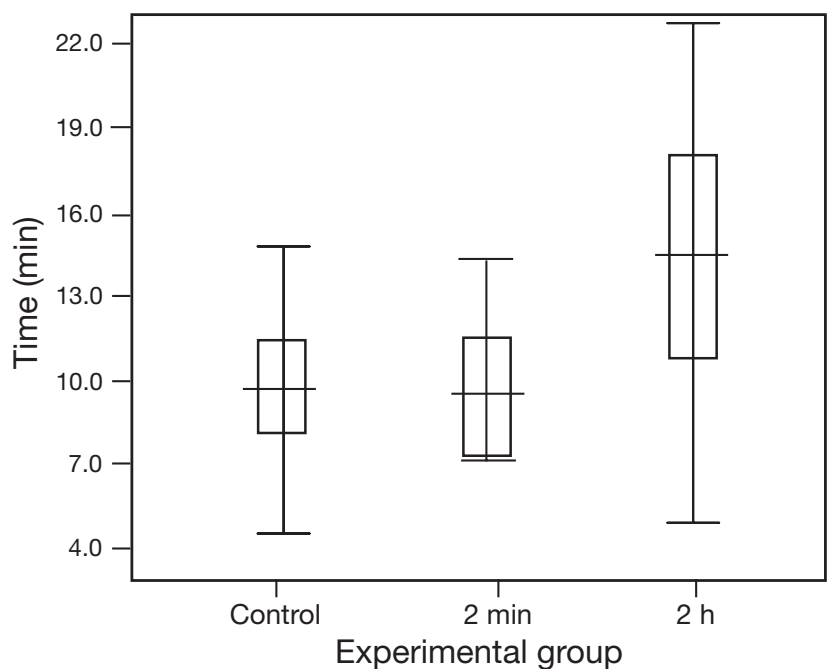

Fig. 3. Time taken by the control, 2 min west, and $2 \mathrm{~h}$ west groups ( $\mathrm{n}=10$ turtles per group) to locate the sea. Horizontal

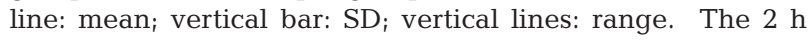
west group differed significantly $(p=0.02)$ from the other 2 groups (see text)
Tukey tests revealed that the $2 \mathrm{~h}$ group differed significantly from the control and the 2 min group, whereas the latter 2 groups were statistically identical.

\section{Crawling orientation}

The control and 2 min west groups crawled on straight paths directly to the sea (Fig. 4, left panel). Both groups were significantly oriented (Fig. 4, right panel; control group: $\mathrm{a}=132^{\circ}$; Rayleigh $\mathrm{z}=9.22, \mathrm{p}<$ $0.05 ; 2$ min group: $\left.\mathrm{a}=136^{\circ} ; \mathrm{z}=8.50, \mathrm{p}<0.05\right)$. The $2 \mathrm{~h}$ group showed weaker orientation, with many turtles crawling on circuitous paths. Two of the 10 turtles in this group failed to locate the surf zone within $25 \mathrm{~min}$ but, as a group, the 10 hatchlings were significantly oriented $\left(\mathrm{a}=129^{\circ}\right.$; Rayleigh $\left.\mathrm{z}=5.73, \mathrm{p}<0.05\right)$. There was no significant difference in orientation among the 3 groups (Watson-Williams test, $F=0.010$, ns).

\section{Swimming distance}

Swimming distances showed a normal distribution in the 2 min west and control groups (Shapiro-Wilk tests: 2 min group, $p=0.28$; controls, $p=0.41$ ), but not in the 2 h west group $(p=0.004)$. The 2 h group swam somewhat farther from shore $($ median $=212.5 \mathrm{~m}$; range $=82.2$ 


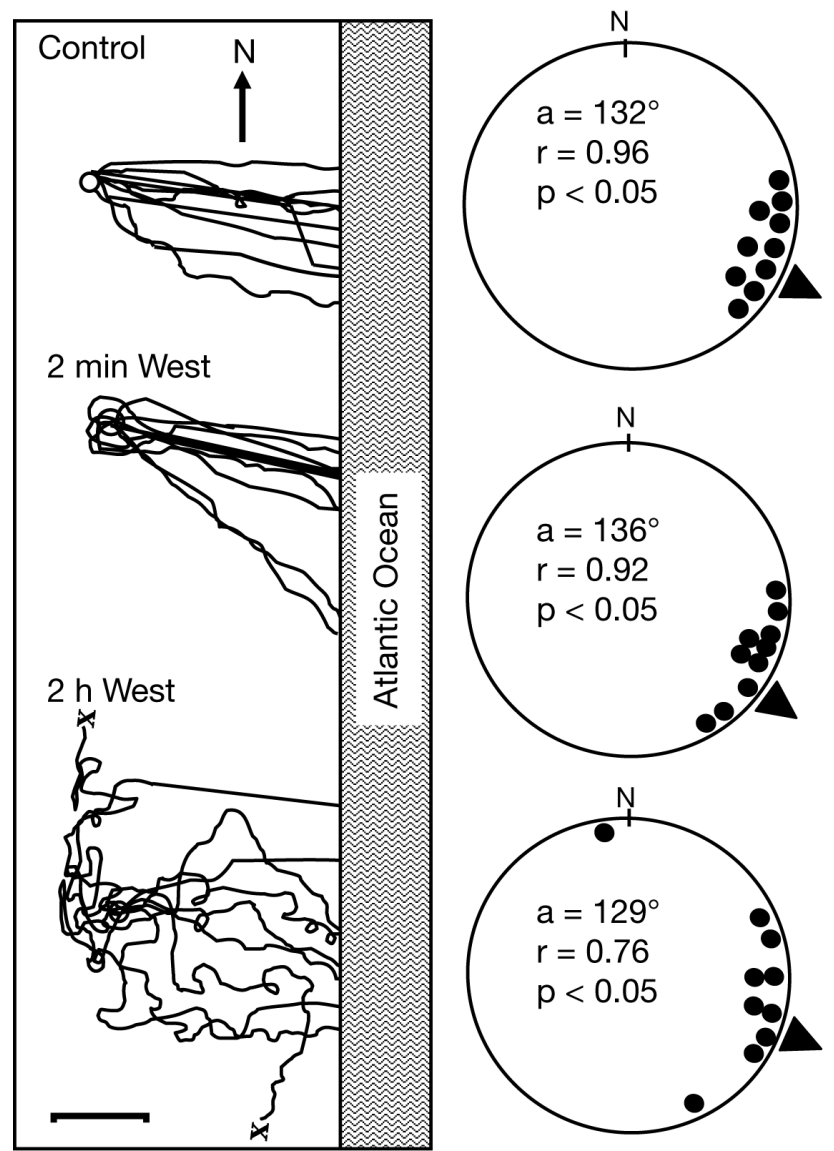

Fig. 4. Crawling paths (left panel) and orientation (right) of the control, 2 min west, and $2 \mathrm{~h}$ west groups. Scale bar: $4 \mathrm{~m}$. $\mathrm{X}$ : final location of 2 turtles in the $2 \mathrm{~h}$ west group that failed to find the ocean. For details of abbreviations see Fig. 2

-230.9) than either the control (median $=175.5 \mathrm{~m}$; range $=136.8-246.1)$ or the 2 min $($ median $=185.2 \mathrm{~m}$; range $=$ 105.4 - 234.1) groups (Fig. 5) but these differences were not statistically significant (Kruskal-Wallis $H=0.705$, ns).

\section{Swimming orientation}

All 3 groups were significantly oriented to the east (Fig. 5). The groups showed no statistical differences in orientation (Watson-Williams $F=0.01$, ns) or in dispersion (Kruskal-Wallis $H=0.072$ ).

\section{DISCUSSION}

Our results show that a misoriented crawl affects the subsequent ability of hatchlings to orient, both on land (Figs. $3 \& 4$ ) and in the ocean (Fig. 2). A long (2 h) misdirected crawl weakens the ability of the turtles to crawl on straight paths to the sea, and lengthens the time required to reach the surf zone. We conclude that a long misoriented crawl temporarily interferes with the ability of the turtles to respond appropriately to the cues normally used to locate the sea. A few turtles (2 of the 10 tested) were so severely affected that they failed to find the ocean (Fig. 4). However, all of the turtles oriented away from the shore when waves were present (Fig. 5), indicating that under those conditions, orientation on land and orientation in the ocean are functionally autonomous (Lohmann et al. 1990).

A short (2 min) misdirected crawl had no effect on either seafinding (Fig. 4) or swimming orientation (Fig. 2) when waves were present. In the absence of surface waves, however, previously misdirected turtles placed in the sea could not orient away from the shore (Fig. 2). These experiments show that when waves are absent, offshore orientation depends upon completing a seaward-directed crawl, and is not functionally autonomous.

Determining why this effect occurred was beyond the scope of our study. Based upon laboratory experiments, in which turtles were induced to either crawl (Lohmann et al. 1995) or swim (Lohmann \& Lohmann 1994) west, we hypothesize that most of our hatchlings were responding to magnetic cues directing them west. However, westward movement was impossible because the shoreline was a barrier to movement in that direction.

\section{Management implications}

The purpose of this study was to determine if the current Guidelines are adequate for the rescue of previously misoriented turtles. The Guidelines emphasize the importance of releasing the turtles on the beach so that they can crawl to the ocean on their own. This recommendation should enable most of the turtles found on the beach, and whose previous interactions with lighting are unknown, to recover and regain the capacity to respond appropriately to orientation cues on land and in the sea. However, our results also suggest that some refinement to those procedures would be beneficial.

Our experiments show that if the turtles have been misoriented for $2 \mathrm{~h}$, the recovery process (as defined by locating the ocean) may take some time (an average of 14.4 min [Fig. 3]), requiring that the turtles complete a crawl of sufficient duration. That can only happen if hatchlings are released at an appropriate distance from the surf zone; the Guidelines, however, do not indicate where release should occur. For loggerheads, we chose $13 \mathrm{~m}$ from the surf zone, the average distance between 10 consecutively placed loggerhead nests and the ocean at each of 4 nesting beaches in Florida 


\section{Control 2 min west 2 h west}

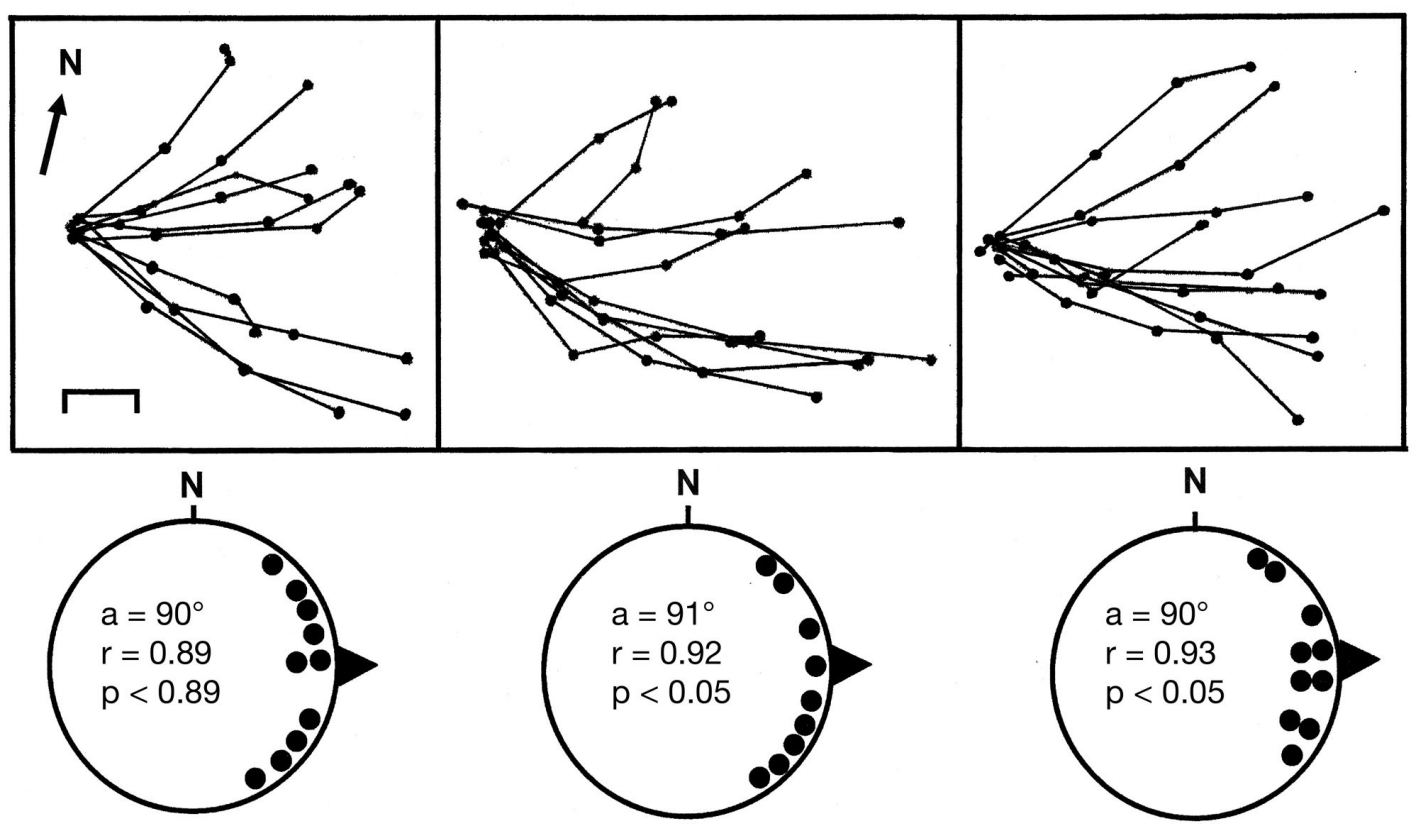

Fig. 5. Swimming paths (top panels) and orientation (bottom panels) for the control, 2 min west, and 2 h west groups used in the 'long crawl' tests. Scale bar and abbreviations as in Fig. 2

(Melbourne Beach, Juno Beach, Normandy Beach, and North Hillsboro; Barrett 2004).

We recommend that the Guidelines adopt this distance for Florida loggerheads, and (based upon comparable measurements) also specify distances appropriate for the release of green turtle and leatherback hatchlings. The Guidelines should also state that if crawling turtles fail to locate the water from those sites, they should not be released when surface waves are absent.

It might be argued that when waves are present, our results make a case for dispensing with a beach crawl altogether. Why not release turtles directly into shallow water, since all of the hatchlings so treated in our study swam away from the shore? There are 3 reasons why this provision should remain in the Guidelines. First, there is the possibility that turtles deprived of a beach crawl might be compromised in their orientation capabilities at a later stage of migration. Second, the beach crawl might provide information that is used for natal beach (or area) imprinting. Given our lack of knowledge about both of these aspects of sea turtle biology, the best policy is to be conservative and to emulate as closely as possible what the turtles typically experience under natural conditions.

The third reason for requiring a beach crawl is that it can be used to evaluate each turtle's behavioral and/or physiological state. This information is essential for deciding whether a turtle should be released or retained for rehabilitation.

\section{Turtles that crawl poorly}

The Guidelines make clear that when turtles are found on the beach, their behavior (as judged by an ability to orient seaward) can vary. Instructions then follow on how to release those turtles. Some hatchlings will crawl seaward, but others '...may need assistance in reaching the water. In such cases, they may be moved closer to the water's edge or placed in the shallows and allowed to swim off on their own'.

None of the turtles used in our experiments were incapable of crawling and only 2 individuals, of the 30 that crawled on the beach (Fig. 4), failed to locate the sea (within $25 \mathrm{~min}$ ). But turtles found on the beach may have been exposed to more extreme lighting (or other) conditions and may crawl weakly, or not at all (if, for example, they are exhausted or dehydrated; Witherington \& Martin 1996). Placing those compromised turtles closer to the water, or in the water itself, often results in their reappearance (a few minutes later) in the surf zone. The Guidelines should therefore instruct beach managers to conduct a careful search for turtles in shallow water over a brief (10 to $15 \mathrm{~min}$ ) period after their release. Any hatchlings that fail to depart should be recaptured, brought to a rehabilitation center for treatment, and released later.

The Guidelines also consider what to do with hatchlings found at different times. 'Small numbers of hatchlings $(<5)$ that are found disoriented... may also be released on the beach immediately (but no later than 
9:00 h). Otherwise, rescued hatchlings must be released the following night...' The Guidelines continue by describing how to hold turtles overnight for later release.

We tentatively agree, but recommend that experiments should be carried out to compare the behavior of these turtles (their crawl on land and their orientation while swimming away from the shore) when released on the evening they are found, with those held overnight and released the next evening. Such a comparison, which to our knowledge has never been made, could be used to determine whether delayed release is an appropriate management option, or whether these turtles should also be held in captivity for rehabilitation and later released in the open ocean.

Finally, the Guidelines fail to describe the release location, which should not only be on a dark beach but also at different places on that beach each evening. Recent studies show that fish predator concentrations vary with location (Gyuris 1994, Wyneken 2000, Stewart \& Wyneken 2004), and that predators can learn during a single nesting season where hatchlings enter the water most frequently (Wyneken et al. 2000). Varying the release site location is an obvious, and easily achieved, management strategy that reduces those risks (Wyneken et al. 2000).

Acknowledgements. This project was completed by J.K.L. as a Masters thesis in the Department of Biological Sciences, Florida Atlantic University. J. Wyneken and J. Volin served on the thesis committee and provided valuable suggestions. Hatchlings were collected with the assistance of S. Ouellette (Broward County Sea Turtle Protection) and K. Rusenko (Gumbo Limbo Nature Center, Palm Beach County). M. Coyne advised on the use of Maptool. A. Mustakas, D. Indeck, A. Kreymerman, J. Lorne, P. Lorne, and M. Smith assisted in the field tests, and J. Gilner provided statistical advice. Financial support was received from the Boca Raton Garden Club and the Department of Biological Sciences (through a Graduate Scholarship). This project was carried out under Federal (NOAA $;$ No. 1509) and State (Florida permit TP \#173) permits, and approved by the University Institutional and Animal Care Committee. We thank 3 anonymous referees for their constructive comments on an earlier version of this paper.

\section{LITERATURE CITED}

Barrett C (2004) Sensitive periods and the development of sea finding orientation of loggerhead hatchlings (Caretta caretta). Masters thesis, Florida Atlantic University, Boca Raton, FL

Florida Fish and Wildlife Conservation Commission (2002) Sea Turtle Conservation Guidelines: www.myfwc. com/seaturtle/guidelines/MarineTurtleGuidelines.htm

Frick J (1976) Orientation and behavior of hatchling green sea turtles (Chelonia mydas) in the sea. Anim Behav 24:849-857

Goff M, Salmon M, Lohmann KJ (1998) Hatchling sea turtles use surface waves to establish a magnetic compass. Anim Behav 55:69-77

Gyuris E (1994) The rate of predation by fishes on hatchlings of the green turtle (Chelonia mydas). Coral Reefs 13:137-144
Ireland LC, Frick JA, Wingate DB (1978) Nighttime orientation of hatchling green turtles (Chelonia mydas) in the open ocean. In: Schmidt-Koenig K, Keeton WT (eds) Animal migration, navigation, and homing. Springer-Verlag, New York, p 420-429

Limpus CJ (1971) Sea turtle ocean finding behavior. Search 2: 385-387

Lohmann KJ (1991) Magnetic orientation by hatchling loggerhead sea turtles (Caretta caretta). J Exp Biol 155:37-49

Lohmann KJ, Lohmann CMF (1992) Orientation to ocean waves by green turtle hatchlings. J Exp Biol 171:1-13

Lohmann KJ, Lohmann CMF (1994) Acquisition of magnetic directional preference in hatchling loggerhead sea turtles. J Exp Biol 190:1-8

Lohmann KJ, Salmon M, Wyneken J (1990) Functional autonomy of land and sea orientation systems in sea turtle hatchlings. Biol Bull 179:214-218

Lohmann KJ, Lohmann CMF, Callaway JC (1995) Evidence that beach crawl direction sets the magnetic compass in loggerhead hatchlings. In: Richardson JI, Richardson TH (compilers) Proc 12th Annual Workshop on Sea Turtle Biology and Conservation. NOAA Tech Memo NMFSSEFC-361, p 71-72

Lohmann KJ, Witherington BE, Lohmann CMF, Salmon M (1997) Orientation, navigation, and natal beach homing in sea turtles. In: Lutz PL, Musick JA (eds) The biology of sea turtles. CRC Press, Boca Raton, FL, p 107-135

Salmon M (2003) Artificial night lighting and sea turtles. Biologist 50:163-168

Salmon M, Lohmann KJ (1989) Orientation cues used by hatchling loggerhead sea turtles (Caretta caretta L.) during their offshore migration. Ethology 83:215-228

Salmon M, Wyneken J, Fritz E, Lucas M (1992) Seafinding by hatchling sea turtles: role of brightness, silhouette and beach slope as orientation cues. Behaviour 122:56-77

Stewart KR, Wyneken J (2004) Predation risk to loggerhead hatchlings at a high-density nesting beach in southeast Florida. Bull Mar Sci 74:325-335

Tuxbury SM, Salmon M (2005) Competitive interactions between artificial lighting and natural cues during seafinding by hatchling marine turtles. Biol Conserv 121:311-316

Verheijen FJ (1985) Photopollution: artificial light optic spatial control systems fail to cope with. Incidents, causation, remedies. Exp Biol 44:1-18

Witherington BE (1991) Orientation of hatchling loggerhead turtles at sea off artificially lighted and dark beaches. J Exp Mar Biol Ecol 149:1-11

Witherington BE (1997) The problem of photopollution for sea turtles and other nocturnal animals. In: Clemmons JR, Buchholz R (eds) Behavioral approaches to conservation in the wild. Cambridge University Press, Cambridge, p 303-328

Witherington BE, Martin RE (1996) Understanding, assessing, and resolving light-pollution problems on sea turtle nesting beaches. Fla Mar Res Inst Tech Rep TR-2

Wyneken J (2000) The migratory behavior of hatchling sea turtles beyond the beach. In: Pitcher NJ, Ismail G (eds) Sea turtles of the Indo-Pacific. ASEAN Academic Press, London, p 121-129

Wyneken J, Salmon M, Fisher L, Weege S (2000) Managing relocated sea turtle nests in open-beach hatcheries. Lessons in hatchery design and implementation in Hillsborough Beach, Broward County, Florida, USA. In: Kalb H, Wibbels T (compilers) Proc 19th Annual Sea Turtle Symposium, Miami. US Dept. of Commerce, NOAA Tech Memo NMFS-SEFSC433. Miami, p 193-194

Zar JH (1999) Biostatistical analysis. Prentice-Hall, Uppper Saddle River, New Jersey 